\title{
Use of Sample Hematocrit Value to Correct Blood Tacrolimus Concentration Derived by Microparticle Enzyme Immunoassay
}

\author{
Takashi Tomita,,${ }^{a, f}$ Masato Homma, ${ }^{*, a, b}$ Yuichi Hasegawa, ${ }^{c}$ Hiroshi KoJima, ${ }^{c}$ Nobuhiro OHконсhI, ${ }^{d}$ \\ Tetsuo Hori, ${ }^{e}$ Michio Kaneko, ${ }^{e}$ Yasuko NAKAno,${ }^{f}$ Takashi ToBE,${ }^{f}$ and Yukinao KoHDA ${ }^{a, b}$ \\ ${ }^{a}$ Department of Pharmacy, Tsukuba University Hospital; 2-1-1 Amakubo, Tsukuba, Ibaraki 305-8576, Japan: \\ ${ }^{b}$ Department of Pharmaceutical Sciences, Graduate School of Comprehensive Human Sciences, University of Tsukuba; \\ ${ }^{c}$ Department of Hematology, Graduate School of Comprehensive Human Sciences, University of Tsukuba; ${ }^{d}$ Department of \\ Surgery, Graduate School of Comprehensive Human Sciences, University of Tsukuba; ${ }^{e}$ Department of Pediatric Surgery, \\ Graduate School of Comprehensive Human Sciences, University of Tsukuba; Tennodai 1-1-1, Tsukuba, Ibaraki 305-8575, \\ Japan: and ${ }^{f}$ Department of Medicinal Information, School of Pharmaceutical Sciences, Showa University; 1-5-8 \\ Hatanodai, Shinagawa-ku, Tokyo 142-8555, Japan.
}

Received January 15, 2008; accepted April 6, 2008; published online April 8, 2008

The quality of microparticle enzyme immunoassay (MEIA) for blood tacrolimus is guaranteed in samples with hematocrit (Ht) values of 25 to $45 \%$. Because MEIA provides inaccurate blood tacrolimus concentrations in samples with $\mathrm{Ht}$ out of this range (i.e. $<25 \%$ or $>\mathbf{4 5 \%}$ ), correction of the calibration is required for therapeutic drug monitoring. The authors demonstrated previously that overestimated MEIA tacrolimus concentration could be corrected by modified, calibrated MEIA (cMEIA) using the original calibrator. Here, an equation was established to more easily derive a corrected tacrolimus concentration by calculation (MEIAcalc) using the Ht of each sample. The tacrolimus concentrations of 99 whole-blood samples with low $\mathrm{Ht}(<25 \%)$ were then tested by the 3 assay methods: MEIA, cMEIA, and MEIAcalc. MEIA gave a significantly higher blood concentration of tacrolimus (median $12.9 \mathrm{ng} / \mathrm{ml}$, range $3.6-26.4 \mathrm{ng} / \mathrm{ml}$ ) than did cMEIA (median $10.0 \mathrm{ng} / \mathrm{ml}$, range 0.2$21.1 \mathrm{ng} / \mathrm{ml}, \boldsymbol{p}<0.05)$. This overestimation was eliminated by using MEIAcalc. There was no difference in blood tacrolimus concentration between cMEIA and MEIAcalc (median $10.0 \mathrm{ng} / \mathrm{ml}$, range $1.7-21.4 \mathrm{ng} / \mathrm{ml}$ ). MEIAcalc can be used to correct the tacrolimus concentration in samples obtained from patients with unstable Ht values.

Key words tacrolimus; hematocrit value; overestimation; microparticle enzyme immunoassay; therapeutic drug monitoring

Tacrolimus is a potent immunosuppressive drug for averting allograft rejection in organ transplantation. ${ }^{1)}$ Trough tacrolimus concentration monitoring is required to obtain optimal doses for individual patients. ${ }^{2,3)}$ The most common methodologies for determining blood tacrolimus concentrations are immunoassays, i.e., microparticle enzyme immunoassay (MEIA) and enzyme-linked immunosorbent assay (ELISA). These immunoassays sometimes provide inaccurate tacrolimus concentrations because of cross-reactivity with tacrolimus metabolites. ${ }^{4)}$ The authors have found that MEIA of blood samples from patients not being treated with tacrolimus can yield false positive results. ${ }^{5-7)}$ These false-positive tacrolimus concentrations are associated with low hematocrit $(\mathrm{Ht})$ values $(<25 \%)$ but not with cross-reactivity of tacrolimus metabolites, because similar results have not been observed by ELISA of samples with low $\mathrm{Ht}$ $(<25 \%) .^{5-8)}$ To eliminate overestimations associated with this false positivity, the authors developed an alternative, calibrated MEIA (cMEIA), using the original calibrator as a background sample, the Ht value of which was adjusted to the same as that of each assay sample. ${ }^{9)}$ This correction method, however, is tedious for routine tacrolimus assay.

The aim of this study was to develop a mathematical correction to account for the analytical error associated with variable $\mathrm{Ht}$ in the tacrolimus MEIA.

\section{MATERIALS AND METHODS}

Samples From 9 transplant recipients (3 liver, 1 kidney, and 5 bone marrow) receiving tacrolimus a total of 124 whole-blood samples were obtained (63 from the liver recipi- ents, 5 from the kidney recipients, and 56 from the bone marrow recipients). All samples had a low $\mathrm{Ht}(<25 \%)$ and were therefore in the category in which the quality of the tacrolimus assay by MEIA could not be guaranteed. This study was approved by the Ethical Committee of University of Tsukuba. Informed consent was obtained from each patient.

Tacrolimus Assay To compare the 3 methods of measurement of tacrolimus, i.e., ELISA (PRO-Trac II, DiaSorin, Stillwater, MN, U.S.A.), MEIA (MEIA-II Tacrolimus, IMx; Abbott, Chicago, IL, U.S.A.), and cMEIA, 25 whole-blood samples were obtained (19 from 1 liver recipient and 6 from 1 bone marrow recipient), ${ }^{9)}$ and an equation to correct MEIA tacrolimus concentration (calculated MEIA: MEIAcalc) was developed. cMEIA, MEIA, and MEIAcalc were then applied to 99 whole-blood samples (44 from 2 liver recipients, 5 from 1 kidney recipient, and 50 from 4 bone marrow recipients) for comparison of the results among the 3 methods. ELISA could not be applied to these samples because of insufficient sample volume.

Blood tacrolimus concentrations were determined by MEIA by using an IMx analyzer (Abbott) in accordance with the manufacturer's instructions. MEIA is a 1-step competitive fluoroimmunoassay in which microparticles coated with monoclonal anti-tacrolimus antibody are the capture reagent and tacrolimus-conjugated alkaline phosphatase is the competitive reagent. The fluorescent product generated by alkaline phosphatase on the substrate, 4-methylumbelliferyl phosphate, is measured using an IMx analyzer. The detected signal is inversely proportional to the tacrolimus concentration in the sample. The coefficients of variation for inter-day 
assay in our laboratory were $6.0 \%, 4.5 \%$, and $2.7 \%$ at concentrations of $5.0,11.0$, and $22.0 \mathrm{ng} / \mathrm{ml}$, respectively. A mode-1 calibrator (Abbott) was used for daily correction of the calibration curve in addition to the mode- 1 calibration correction stated. The assay procedure used in cMEIA was the same as that in MEIA, with the exception of the mode-1 calibrator. In cMEIA, whole-blood samples collected from healthy subjects who had not receive tacrolimus were used instead of the mode-1 calibrator. The Ht value of the wholeblood sample was adjusted to make it the same as that of each assay sample by removing plasma or adding saline. We confirmed the difference between MEIA and cMEIA in a series of control samples (tacrolimus concentration $5.0 \mathrm{ng} / \mathrm{ml}$ ) prepared with $\mathrm{Ht}$ value of 15 to $55 \%$. $^{9)}$ Maximal overestimation by MEIA and cMEIA was $4.1 \mathrm{ng} / \mathrm{ml}(82 \%)$ and $0.8 \mathrm{ng} / \mathrm{ml}(16 \%)$, respectively, in assay sample with Ht value of $15 \%{ }^{9)}$

An equation for MEIAcalc was constructed to correct the MEIA tacrolimus concentration by using the $\mathrm{Ht}$ value of each assay sample. In MEIA for measurement of tacrolimus by using the mode- 1 calibrator, the relationship between the fluorescent rate and the tacrolimus concentration follows a sigmoid inhibitory maximum effect model:

$$
\begin{aligned}
& \text { fluorescent rate }_{(\text {mode-1 })}=E_{\max (\text { mode-1 })}-\left(E_{\max (\text { mode- } 1)}-E_{0(\text { mode-1 })}\right) \\
& \times\left[C^{\gamma} /\left(C^{\gamma}+\mathrm{EC}_{50}{ }^{\gamma}\right)\right]
\end{aligned}
$$

Where $C$ is the concentration of tacrolimus determined by MEIA using the mode- 1 calibrator $(\mathrm{ng} / \mathrm{ml}) ; E_{\max (\text { mode- } 1)}$ is the fluorescent rate at $C=0 ; E_{0 \text { (mode- })}$ is the fluorescent rate at $C=$ infinity; $\gamma$ is a sigmoidicity factor; and $\mathrm{EC}_{50}$ is the tacrolimus concentration producing $50 \%$ of the maximum effect. The parameters were calculated by using WinNonlin 4.1 (Pharsight Inc., Mountain View, CA, U.S.A.). The estimates for $E_{\max (\text { mode-1) }}, E_{0 \text { (mode-1) }}, \mathrm{EC}_{50}$, and $\gamma$ were $484.80,40.68$, 8.45 , and 1.25 , respectively.

With these values, Eq. 1 gives Eq. 2:

$$
\text { fluorescent rate } \mathrm{e}_{\text {(mode-1) }}=484.8-444.1 \times C^{1.25} /\left(C^{1.25}+14.4\right)
$$

When MEIAcalc is used to correct the MEIA tacrolimus concentration, the fluorescent rate and the tacrolimus concentration follow a sigmoid inhibitory maximum effect model:

$$
\begin{aligned}
\text { fluorescent rate }_{(\text {mode- } 1)}= & E_{\max (\text { original) }}-\left(E_{\max (\text { original })}-E_{0(\text { original }}\right) \\
& \times[\text { MEIAcalc } \\
1.25 /(\text { MEIAcalc } & 1.25+14.4)]
\end{aligned}
$$

Equation 3 gives Eq. 4.

$$
\text { MEIAcalc }=e^{A / 1.25}
$$

where $A$ is as follows:

$$
\begin{aligned}
A= & \ln \left[14.4 \times\left(\text { fluorescent rate }_{(\text {mode- } 1)}-E_{\max (\text { original })}\right) /\right. \\
& \left.\left(E_{0 \text { (original) }}-\text { fluorescent rate }_{(\text {mode- } 1)}\right)\right]
\end{aligned}
$$

Because $E_{\max (\text { original) }}$ and $E_{0 \text { (original) }}$ are the specific values for each IMx analyzer, they were determined experimentally. The measurements of $E_{\text {max (original) }}$ was made by using of a series of control samples (tacrolimus free) with $\mathrm{Ht}$ value of 11.8 to $60.2 \%$. The relationship between the $E_{\max (\text { original })}$ and the $\mathrm{Ht}$ value is as follows:

$$
E_{\max (\text { original })}=3.03 \times \mathrm{Ht}+350.9
$$

$E_{0 \text { (original) }}$ was calculated as follows:

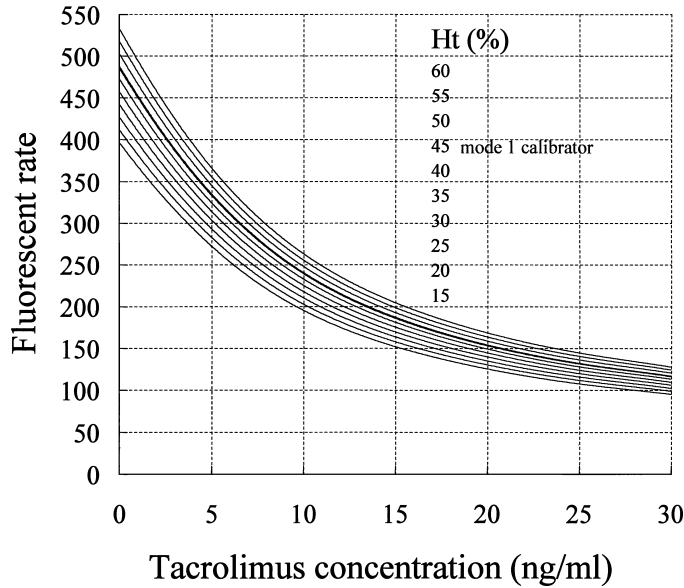

Fig. 1. Effects of Hematocrit Values on Calibration Curves for Determination of Blood Tacrolimus

$$
E_{0 \text { (original })}=40.68 \times\left(E_{\max (\text { original })} / E_{\max (\text { mode- } 1)}\right)=0.084 \times E_{\max (\text { original })}
$$

MEIA determined incorrect blood concentrations of tacrolimus in samples with $\mathrm{Ht}$ values out of the range $(<25 \%$ or $>45 \%$ ). The effects of $\mathrm{Ht}$ on the calibration curve for determination of tacrolimus concentration are shown in Fig. 1.

Statistical Analysis Differences in blood tacrolimus concentration among the assay methods were determined by the Steel-Dwass test. A $p$ value of less than 0.05 was considered statistically significant.

\section{RESULTS}

Twenty-five whole-blood samples with $\mathrm{Ht}$ value $<25 \%$ (median 20.8\%, range $15.6-23.2 \%$ ) were measured by 4 methods: ELISA, MEIA, cMEIA, and MEIAcalc (Table 1). MEIA provided a concentration of $16.1 \mathrm{ng} / \mathrm{ml}$ (range 9.0 $26.0 \mathrm{ng} / \mathrm{ml}$ ), which was significantly higher than that of ELISA (median $11.0 \mathrm{ng} / \mathrm{ml}$, range $7.4-20.0 \mathrm{ng} / \mathrm{ml}, p<0.05$ ) (Table 1). MEIAcalc (median $12.0 \mathrm{ng} / \mathrm{ml}$, range 6.8 $21.0 \mathrm{ng} / \mathrm{ml}$ ) and cMEIA (median $12.3 \mathrm{ng} / \mathrm{ml}$, range $9.2-$ $21.1 \mathrm{ng} / \mathrm{ml}$ ) were in close agreement with ELISA in determining tacrolimus concentration (Table 1). Compared with ELISA, the percentage overestimations with MEIA, cMEIA, and MEIAcalc were $46.4 \%, 11.8 \%$, and $6.4 \%$, respectively. This tendency was almost same when comparison was made between the $\mathrm{Ht}$ values of $15-20 \%$ and $20-25 \%$ (Table 1 ). The slopes of the regression lines between ELISA and cMEIA or MEIAcalc were 0.929 or 0.925 , respectively, which was smaller than that of ELISA and MEIA (1.077) (Fig. 2A).

To compare further the tacrolimus concentrations among MEIA, cMEIA, and MEIAcalc, the 3 methods were simultaneously applied to 99 whole-blood samples with $\mathrm{Ht}$ values $<25 \%$ (median $21.9 \%$, range $13.5-24.9 \%$ ). MEIA gave significantly higher blood concentrations of tacrolimus (median $12.9 \mathrm{ng} / \mathrm{ml}$, range $3.6-26.4 \mathrm{ng} / \mathrm{ml}$ ) than did cMEIA (median $10.0 \mathrm{ng} / \mathrm{ml}$, range $0.2-21.1 \mathrm{ng} / \mathrm{ml}, p<0.05)$ and MEIAcalc (median $10.0 \mathrm{ng} / \mathrm{ml}$, range $1.7-21.4 \mathrm{ng} / \mathrm{ml}, p<0.05$ ) (Table $2)$. MEIA constantly provided greater values compared with MEIAcalc (Fig. 2B). The slopes of the regression lines between cMEIA and MEIA or MEIAcalc were 1.133 or 0.968 , respectively (Fig. 2B). MEIAcalc and cMEIA results were al- 
Table 1. Difference in the Tacrolimus Concentration among ELISA, MEIA, cMEIA, and MEIAcalc

\begin{tabular}{|c|c|c|c|c|c|c|}
\hline Sample $^{a)}$ & & Hematocrit (\%) & ELISA & MEIA & cMEIA & MEIAcalc \\
\hline Hematocrit (\%) & $n$ & Median (Range) & Median (Range) & $\begin{array}{l}\text { Median (Range) } \\
\text { Overestimation }^{b)}\end{array}$ & $\begin{array}{l}\text { Median (Range) } \\
\text { Overestimation }^{c}\end{array}$ & $\begin{array}{l}\text { Median (Range) } \\
\text { Overestimation }^{d)}\end{array}$ \\
\hline & 25 & $20.8(15.6-23.2)$ & $11.0(7.4-20.0)$ & $\begin{array}{c}16.1 *(9.0-26.0) \\
46.4 \%\end{array}$ & $\begin{array}{c}12.3(9.2-21.1) \\
11.8 \%\end{array}$ & $\begin{array}{c}12.0(6.8-21.0) \\
6.4 \%\end{array}$ \\
\hline $15-20$ & 9 & $18.0(15.6-19.1)$ & $11.0(8.6-14.0)$ & $\begin{array}{c}16.2(13.8-22.6) \\
47.3 \%\end{array}$ & $\begin{array}{c}12.0(9.7-17.1) \\
9.1 \%\end{array}$ & $\begin{array}{c}12.0(10.2-17.4) \\
9.1 \%\end{array}$ \\
\hline $20-25$ & 16 & $21.7(20.5-23.2)$ & $11.5(7.4-20.0)$ & $\begin{array}{c}15.3(9.0-26.0) \\
33.1 \%\end{array}$ & $\begin{array}{c}13.0(9.2-21.1) \\
13.1 \%\end{array}$ & $\begin{array}{c}12.0(6.8-21.0) \\
4.4 \%\end{array}$ \\
\hline
\end{tabular}

Significant difference was observed in comparison with ELISA; $* p<0.05$. a) Samples were divided into 2 groups based on the hematocrit value. $b$ ) Percent overestimation was calculated by the formula (MEIA-ELISA)/ELISA $\times 100$. c) Percent overestimation was calculated by the formula (cMEIA-ELISA)/ELISA $\times 100$. $d$ ) Percent overestimation was calculated by the formula (MEIAcalc-ELISA)/ELISA $\times 100$.

Table 2. Difference in the Tacrolimus Concentration among cMEIA, MEIA, and MEIAcalc

\begin{tabular}{|c|c|c|c|c|c|c|c|}
\hline \multirow{2}{*}{$\begin{array}{l}\text { Hematocrit (\%): Median } \\
\text { (Range) }\end{array}$} & \multirow{2}{*}{$n$} & \multirow{2}{*}{ Sample ${ }^{a)}$} & \multirow{2}{*}{$\begin{array}{l}\text { cMEIA: Median } \\
\text { (Range) }\end{array}$} & \multirow{2}{*}{$\begin{array}{l}\text { MEIA: Median } \\
\quad \text { (Range) }\end{array}$} & \multirow{2}{*}{$\begin{array}{l}\text { MEIAcalc: Median } \\
\text { (Range) }\end{array}$} & \multicolumn{2}{|c|}{ Overestimation in } \\
\hline & & & & & & MEIA $^{b)}$ & MEIAcalc ${ }^{c)}$ \\
\hline $21.9(13.5-24.9)$ & 99 & & $10.0(0.2-21.1)$ & $12.9 *(3.6-26.4)$ & $10.0(1.7-21.4)$ & $33.3 \%$ & $1.9 \%$ \\
\hline $23.9(20.9-24.9)$ & 17 & $<5 \mathrm{ng} / \mathrm{ml}$ & $3.0(0.2-4.9)$ & $4.6 *(3.6-9.8)$ & $2.9(1.7-7.7)$ & $63.6 \%$ & $5.4 \%$ \\
\hline $20.7(13.5-24.4)$ & 31 & $5-10 \mathrm{ng} / \mathrm{ml}$ & $7.4(5.0-9.9)$ & $10.2 *(6.0-13.8)$ & $7.5(4.1-10.9)$ & $37.8 \%$ & $3.0 \%$ \\
\hline $20.8(15.6-24.6)$ & 35 & $10-15 \mathrm{ng} / \mathrm{ml}$ & $11.3(10.0-14.7)$ & $14.0 *(11.5-21.0)$ & $10.7(8.7-16.9)$ & $24.0 \%$ & $-3.9 \%$ \\
\hline $22.4(18.0-23.6)$ & 16 & $>15 \mathrm{ng} / \mathrm{ml}$ & $17.4(15.2-21.1)$ & $22.1 *(18.0-26.4)$ & $17.5(14.3-21.4)$ & $28.3 \%$ & $2.8 \%$ \\
\hline
\end{tabular}

Significant differences were observed in comparison with cMEIA; $* p<0.05$. a) Samples were divided into 4 groups based on the tacrolimus concentration, which was determined by cMEIA. $b$ ) Percent overestimation was calculated by the formula (MEIA-cMEIA)/cMEIA $\times 100 . \quad c$ ) Percent overestimation was calculated by the formula $($ MEIAcalc-cMEIA)/cMEIA $\times 100$.
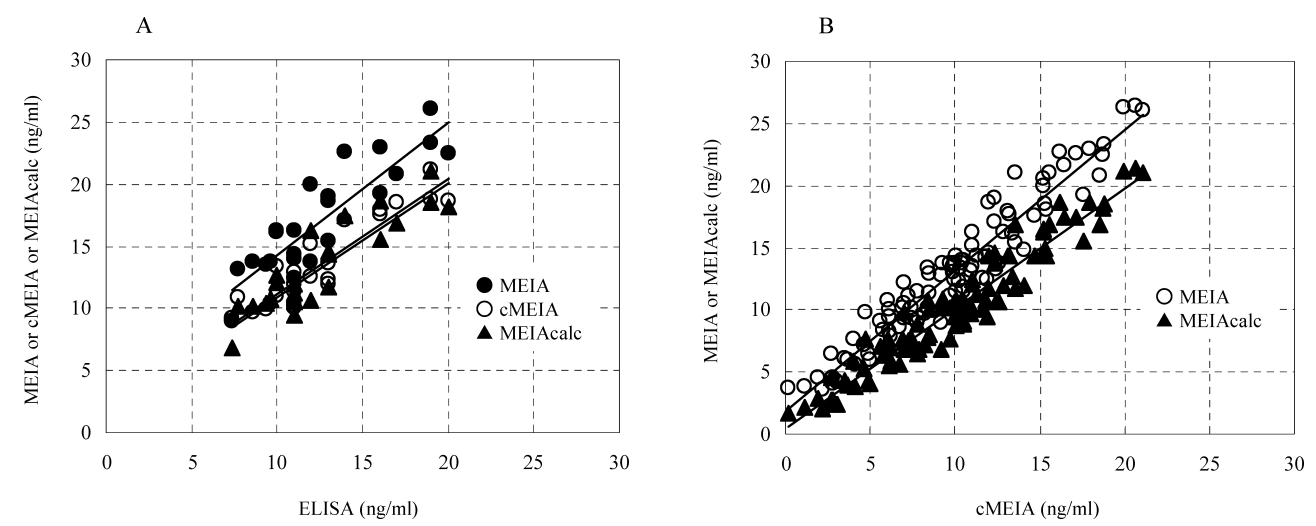

Fig. 2. Relationship of Blood Tacrolimus Concentrations Determined by ELISA, MEIA, cMEIA and MEIAcalc (A) and Determined by cMEIA, MEIA and MEIAcalc (B)

most same throughout the assay range $(0.2-21.4 \mathrm{ng} / \mathrm{ml})$ (Fig. 2B).

\section{DISCUSSION}

MEIA potentially overestimated blood tacrolimus concentration in samples with low $\mathrm{Ht}<25 \%{ }^{5-9)}$ This overestimation may provide inaccurate dose adjustment of tacrolimus in patients with anemia. We experienced a liver transplant case with anemia, who had rejection episodes while Ht values under $25 \%{ }^{5)}$ This may be insufficient immunosuppression due to overestimated concentration of tacrolimus. We, therefore, started measuring $\mathrm{Ht}$ values routinely in the case with anemia.

Therapeutic range for tacrolimus determined by MEIA has been reported in many clinical institutions, where the Ht val- ues of the samples have not been examined. ${ }^{3)}$ In our previous study, around $30 \%$ of the samples for therapeutic drug monitoring (TDM) of tacrolimus had abnormal $\mathrm{Ht}$ values in organ transplantations. ${ }^{9)}$ Especially in bone marrow transplant recipients, $60 \%$ of the assay samples for tacrolimus TDM showed lower Ht values, which may provide overestimated data when MEIA is employed for tacrolimus TDM, though the clinical significance was unclear. The effects of $\mathrm{Ht}$ value on tacrolimus TDM has been reported in other institutions, where the plasma fraction of tacrolimus was altered under abnormal Ht values. ${ }^{10)}$

Our previous study demonstrated that inaccurate blood tacrolimus concentration derived by MEIA could be corrected by cMEIA using the original calibrator. ${ }^{9)}$ There was a negligible difference in blood tacrolimus concentration between cMEIA and ELISA in samples with low $\mathrm{Ht}<25 \%$. ${ }^{9}$ 
This means that cMEIA is an alternative method of obtaining reasonably accurate tacrolimus concentrations in samples with low $\mathrm{Ht}$ values. cMEIA, however, requires a tedious assay procedure that uses a corrected mode- 1 calibrator: a whole-blood blank must be prepared with an Ht value the same as that of the assay sample. To solve this problem, we developed an equation (MEIAcalc) to correct MEIA tacrolimus concentration by using the Ht value of each assay sample. We examined the difference in the tacrolimus concentrations determined by MEIAcalc and ELISA of samples with $\mathrm{Ht}$ values $<25 \%$. The difference between MEIAcalc and ELISA was not significant in samples with low $\mathrm{Ht}$ values (median 20.8\%) (Table 1). No critical difference in results, in terms of overestimation, was observed between MEIAcalc and ELISA. A good correlation between MEIAcalc and cMEIA was also found (Fig. 2B). The slope of the regression line between MEIAcalc and cMEIA was 0.968. This means that the application of MEIAcalc could easily provide corrected tacrolimus concentrations for samples obtained from patients with low Ht values.

Several pitfalls in the use of immunoassay monitoring of tacrolimus should be considered. First, MEIA potentially overestimates blood tacrolimus concentration in whole-blood samples with low Ht values. ${ }^{11,12)}$ A positive bias of $46 \%$ was evident between MEIA and ELISA in assay samples with low $\mathrm{Ht}$ values $(<25 \%)$ (Table 1$)$. Second, immunoassays cannot avoid substantial cross-reactivity of tacrolimus metabolites against anti-tacrolimus antibody, even when monoclonal antibody is used. ELISA provides a positive bias of $10 \%$ in determining tacrolimus concentration compared with high-performance liquid chromatography-tandem mass spectrometry (HPLC-MS-MS). ${ }^{13,14)}$ MEIAcalc can solve the former problem as well as cMEIA and ELISA can. A way of solving the latter problem other than by using HPLC-MS-MS remains to be clarified.

Acknowledgments This work was supported in part by Grant-in-Aid for Scientific Research (Encouragement of Scientists) no. 16922080 from the Japan Society for the Promotion of Science.

\section{REFERENCES}

1) Plosker G. L., Foster R. H., Drugs, 59, 323-389 (2000).

2) Armstrong V. W., Oellerich M., Clin. Biochem., 34, 9-16 (2001).

3) Oellerich M., Armstrong V. W., Schütz E., Shaw L. M., Clin. Biochem., 31, 309-316 (1998).

4) Staatz C. E., Taylor P. J., Tett S. E., Ther. Drug Monit., 24, 607-615 (2002).

5) Homma M., Tomita T., Yuzawa K., Takada Y., Kohda Y., Biol. Pharm. Bull., 25, 1119-1120 (2002).

6) Tomita T., Homma M., Itagaki F., Yamamoto Y., Kakiuchi Y., Yuzawa K., Fukao K., Kohda Y., Jpn. J. Ther. Drug Monit., 20, 30-34 (2003).

7) Taylor P. J., Morris R. G., Ther. Drug Monit., 25, 259-260 (2003).

8) Kuzuya T., Ogura Y., Motegi Y., Moriyama N., Nabeshima T., Ther. Drug Monit., 24, 507-511 (2002).

9) Tomita T., Homma M., Yuzawa K., Ohkohchi N., Hori T., Kaneko M., Hasegawa Y., Kojima H., Nagasawa T., Kohda Y., Ther. Drug Monit., 27, 94-97 (2005)

10) Minematsu T., Sugiyama E., Kusama M., Hori S., Yamada Y., Ohtani H., Sawada Y., Sato H., Takayama T., Sugawara Y., Makuuchi M., Iga T., Transplant. Proc., 36, 1506-1511 (2004).

11) Armendáriz Y., García S., Lopez R. M., Pou L., Ther. Drug Monit., 27, $766-769$ (2005)

12) Napoli K. L., Ther. Drug Monit., 28, 491-504 (2006).

13) MacFarlane G. D., Shaw L. M., Venkataramanan R., Mullins R., Scheller D. G., Ersfeld D. L., Ther. Drug Monit., 21, 585-592 (1999).

14) MacFarlane G. D., Scheller D. G., Ersfeld D. L., Shaw L. M., Venkatarmanan R., Sarkozi L., Mullins R., Fox B. R., Clin. Chem., 45, 1449-1458 (1999). 